\title{
Recycling Waste Plastic into Fuel Products
}

\author{
B S S Phanisankar ${ }^{1}$, N Vasudev Rao ${ }^{2}$, N S G Saranya ${ }^{3}$ \\ Department of Mechanical Engineering ${ }^{1,2,3}$, Assistant Professor ${ }^{1,3}$, Associate Professor ${ }^{2}$. \\ Email: Phanisankar.bandaru@gmail.com ${ }^{1}$,nvdrao@hotmail.com ${ }^{2}$,saranya.nukala@gmail.com ${ }^{3}$
}

\begin{abstract}
Environmental issues associated with waste plastics are a worldwide concern.India has perceived generous growth both in production and intake of plastics. In nonexistence of proper waste collection and discrimination processes, the management of the waste especially for unwanted plastic used for packaging, has become a challenging task. Most of pollution boards in India, filed information on plastic waste generation in 2017-18, according to the latest report of the Central Pollution Control Board (CPCB). Thus, the CPCB estimate of plastic waste generated in India in 2017-18 was 660,787.85 tones, enough to fill 66,079 trucks at 10 tones a truck--does not reflect the situation in more than $60 \%$ of India's states and union territories.Presently, incinerators or Waste-to-energy (WTE) plants are positioned as the modus operandi for waste treatment for the purpose of deriving energy from waste, and at the same time minimize the amount of solid waste sent to landfills. However, reports have shown that significant amounts of greenhouse gas emissions are generated from WTE systems.Pyrolysis of waste plastic is a probable way of conversion of waste plastic into low emissive hydrocarbon fuel. In pyrolysis process, the plastic waste is not burned. But instead plastic is chemically broken down into pyrolysis oil, Hydro carbon gas and carbon black. Plastic to oil conversion is environmental friendly technology for disposal of plastic waste.
\end{abstract}

Index Terms-Plastic waste management, Recycle, Pyrolysis and alternative to fuels.

\section{INTRODUCTION}

Plastics play animportant role in day- today life. It is unique material because of their toughness, light weight, resistance to water and chemicals, resistant to heat and cold, low electrical and thermal conductivity, ease of fabrication, remarkable color range, more design flexibility, durability and energy efficiency. Due to above properties it is used in packaging materials, agriculture, construction, insulation, automobile sector, electronic devices, textiles and sports equipment and toys.

Plastics constitutes in two main categories. It is thermoplastics and thermoset plastics. Thermoplastics make up $80 \%$ of the plastics and thermoset plastics make up of remaining $20 \%$ of plastics producedtoday.Thermo plastics can re-melt or remould and therefore it recyclable easily but thermoset plastics cannot re-melt or reshape and therefore it is difficult to recycling. Use of different type of some thermo plastics is given in table1 below. Plastics are relatively cheap, easy available, easy to manufacture and their versatility replace to conventional materials. Plastic waste management is biggest problem now due to their nonbiodegradability nature. Now plastics manage by plastics recycling technologies.

\section{PLASTICS}

As a brief introduction to plastics, it can be said that plastics are synthetic organic materials produced by polymerization. They are typically of high molecular mass, and may contain other substances besides polymers to improve performance and/or reduce costs. These polymers can be moulded or extruded into desired shapes.

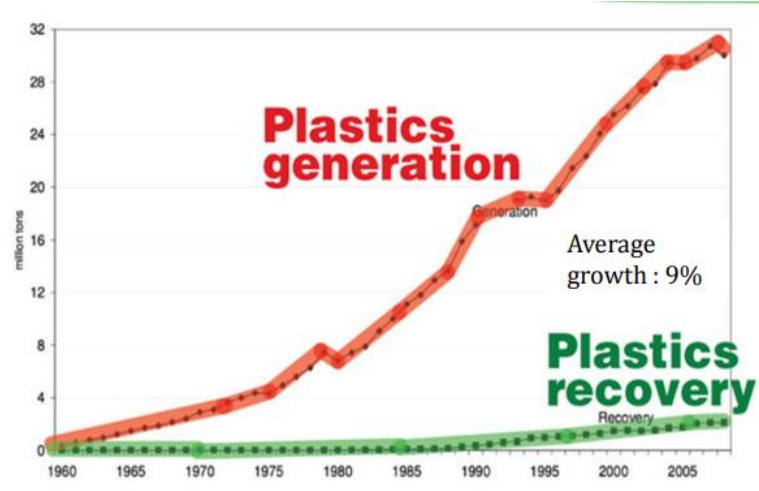

Graph 1. Plastic generation \& Recovery

There are two main types of plastics: thermoplastics and thermosetting polymers. Thermoplastics can repeatedly soften and melt if enough heat is applied and hardened on cooling, so that they can be made into new plastics products. Examples are polyethylene, polystyrene and polyvinyl chloride, among others. 2) Thermosets or thermosettings can melt and take shape only once. They are not suitable for repeated heat treatments; therefore after they have solidified, they stay solid. B. Target Waste Plastics Waste plastics are one of the most promising resources for fuel production because of its high heat of combustion and due to the increasing availability in local communities. Unlike paper and wood, plastics do not absorb much moisture and the water content of plastics is far lower than the water content of biomass such as crops and kitchen wastes. The conversion methods of waste plastics into fuel depend on the types of plastics to be targeted and the properties of other wastes that might be used in the process. 


\section{Available online at www.ijrat.org}

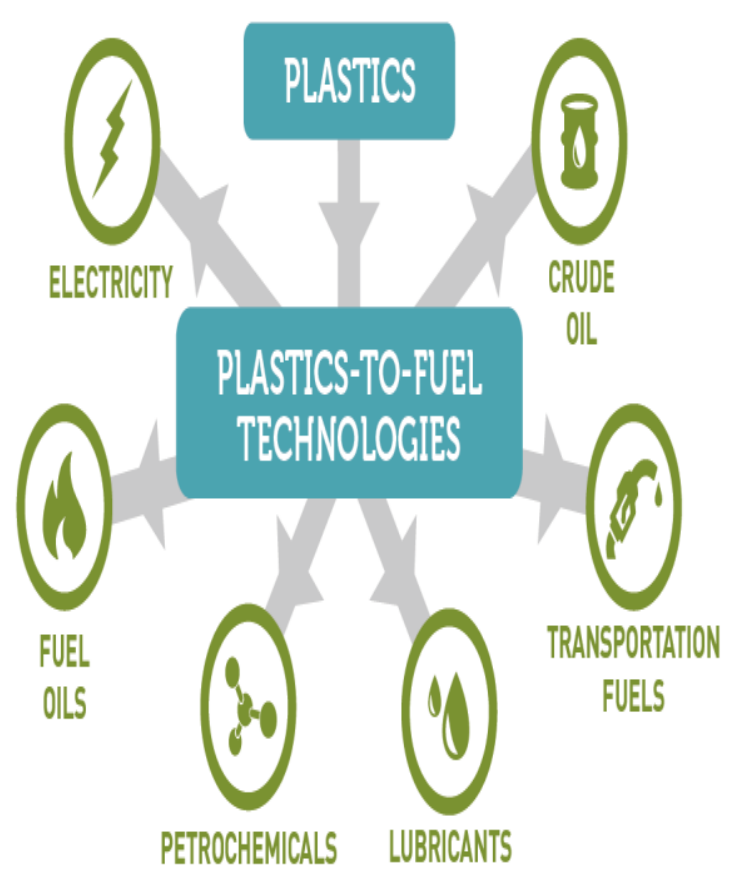

Fig. 1 Plastic to Fuel Technologies

Additionally the effective conversion requires appropriate technologies to be selected according to local economic environmental, social and technical characteristics. In general, the conversion of waste plastic into fuel requires feedstock which arenonhazardous and combustible. In particular each type of waste plastic conversion method has its own suitable feedstock. The composition of the plastics used as feedstock may be very different and some plastic articles might contain undesirable substances (e.g. additives such as flame retardants containing bromine and antimony compounds or plastics containing nitrogen, halogens, sulphur or any other hazardous substances) which pose potential risks to humans and to the environment. The types of plastics and their composition will condition the conversion process and will determine the pretreatment requirements, the combustion temperature for the conversion and therefore the energy consumption required, the fuel quality output, the flue gas composition (e.g. formation of hazardous flue gases such as NOx and $\mathrm{HCl}$ ), the fly ash and bottom ash composition, and the potential of chemical corrosion of the equipment, Therefore the major quality concerns when converting waste plastics into fuel resources are as follows:

1) Smooth feeding to conversion equipment: Prior to their conversion into fuel resources, waste plastics are subject to various methods of pre-treatment to facilitate the smooth and efficient treatment during the subsequent conversion process. Depending on their structures (e.g. rigid, films, sheets or expanded (foamed) material) the pre-treatment equipment used for each type of plastic (crushing or shredding) is often different.
2) Effective conversion into fuel products: In solid fuel production, thermoplastics act as binders which form pellets or briquettes by melting and adhering to other non-melting substances such as paper, wood and thermosetting plastics. Although wooden materials are formed into pellets using a pelletize, mixing plastics with wood or paper complicates the pellet preparation process. Suitable heating is required to produce pellets from thermoplastics and other combustible waste. In liquid fuel production, thermoplastics containing liquid hydrocarbon can be used as feedstock. The type of plastic being used determines the processing rate as well as the product yield. Contamination by undesirable substances and the presence of moisture increases energy consumption and promotes the formation of byproducts in the fuel production process.

3) Well-controlled combustion and clean flue gas in fuel user facilities: It is important to match the fuel type and its quality to the burner in order to improve heat recovery efficiency. Contamination by nitrogen, chlorine, and inorganic species, for instance, can affect the flue gas composition and the amount of ash produced. When using fuel prepared from waste plastics, it must be assured that the flue gas composition complies with local air pollution regulations. In the same way, ash quality must also be in compliance with local regulations when disposed at the landfill. If there aren't any relevant regulations, both the producers and consumers of the recycled fuel should control the fuel quality and the emissions at combustion in order to minimize their environmental impact. C. Fuel Demand The present rate of economic growth is unsustainable without saving of fossil energy like crude oil, natural gas or coal. International Energy Outlook 2010 reports the world consumption of liquid and petroleum products grows from 86.1 million barrels per day in2007 to 92.1 million barrels per day in 2020 and 110.6 million barrels per day in 2035 and natural gas consumption increases from 108 trillion cubic feet in 2007 to 156 trillion cubic feet in 2035. This way, the oil and gas reserve available can meet only 43 and 167 years further. Thus mankind has to rely on the alternate/renewable energy sources like biomass, hydropower, geothermal energy, wind energy, solar energy, nuclear energy, etc.

\subsection{Target Of Waste Plastics Into Liquid Fuel:}

Recycling Technologies:

1. Mechanical Recycling of waste plastics into reusable product is difficult and unfeasible due to contamination of plastics, difficulty to identifying and separating different type of plastics.

2. Uncontrolled incineration of plastics at higher temp above 850 deg Celsius to produces polychlorinated dibenzo-p-dioxins, a carcinogen (cancer causing chemical). Open-air burning of plastic occurs at lower temperatures, and normally releases such toxic fumes and many oxide gases. So flue gases treatment use for protect environment and health problems in incineration plant. 


\section{Available online at www.ijrat.org}

3. Chemical recycling could lead to useful raw materials via by degradation and monomerization of plastics waste, but no method of this primary recycling currently available. The degradation of some plastics into chemicals has been reported in research level. Gasification and blast furnace of plastics waste to produce gases that are carbon dioxide, nitrogen, carbon mono oxide, hydrogen and methane at higher temp above $800 \mathrm{deg}$. Celsius.

\section{BIODEGRADABILITY:}

Plastics are non-biodegradable material that resists microbial attack. Though work has been done to make futuristic biodegradable plastics, there have not been many conclusive steps towards cleaning up the existing problem because prices of biodegradable plastics is more than petrochemicals based plastics. It may be due to high cost of production and low availability or high cost of raw materials. Some degradable plastics have been developed, but none has proved compatible with the conditions required for most waste landfills. Thus, there is an environmental problem associated with the disposal of plastics.

\section{PLASTICS RECYCLING TECHNOLOGIES:}

Recycling of plastics should be carried in a manner to minimize pollution during the process and enhance efficiency and conserve the energy. There is different type of technology include following aspect:

1. Mechanical Recycling- Recycling of plastics waste into reusable product.

2. Chemical Recycling - Gasification, blast furnace

3. Incineration- Burning of waste plastics to obtain energy.

4. Pyrolysis - Conversion of waste plastics into liquid fuels.

4.1 Pyrolysis:

It is thermal degradation process in the absence of oxygen. It prevent of formation of $\mathrm{COX}$, NOX, SOX due to absence of oxygen. It breaks large hydrocarbon chain into smaller ones, but this type of pyrolysis requires higher temperature and high reaction time. Also resulting fluid have low octane value, higher pour point of diesel and high residue content.

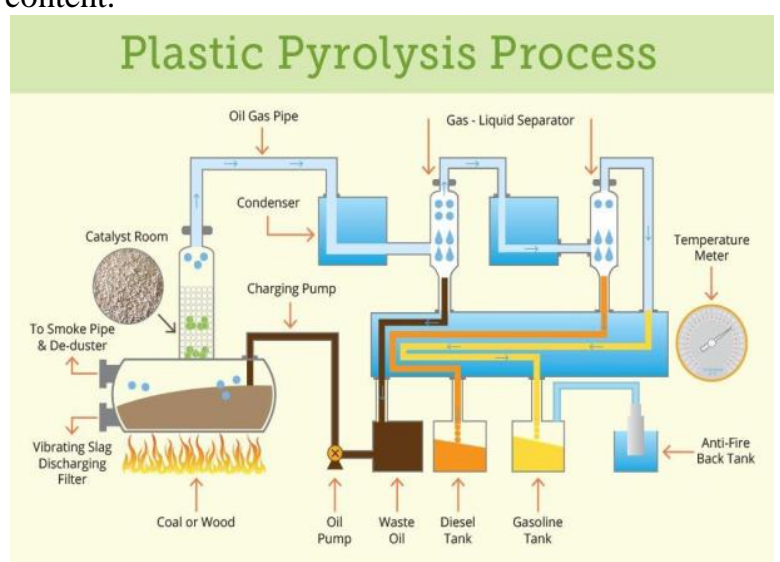

Fig 2. Plastic Pyrolysis Process

\subsection{Catalytic Pryolysis;}

Pyrolysis of waste plastics in presence of catalyst lower the pyrolysis temp and reaction time, increase conversion rate of waste plastics into fuel, increase the yield of fuel and satisfying diesel, petrol quality of fuel by increase octane value of petrol and decrease.

\section{PROCESS OF FORMATION:}

Collect waste plastics and separate that clean and recyclable. Store the waste plastics that can't separate. Shredding of waste plastics to reduce volume of its. Shredded plastics is treated in a cylindrical reactor at temperature of $300^{\circ} \mathrm{C}-350^{\circ} \mathrm{C}$.Plastics waste further cracked with catalyst and resulting hydrocarbons are condensed from water cool condenser and collected in receiver. Then liquid fuel fractionates to get diesel, kerosene, petrol etc. Gases produced are toxic, corrosive with non-toxic gases. For example hydrogen chloride, hydrogen sulfide etc. is toxic and nontoxic is butanes, methane, ethane and propylene. So all the gases are treated from this process before it discharge into atmosphere. Therefore flue gas treated through scrubbers and water/ chemical treatment for neutralization i.e. Solution of methanol amine is use in hydrogen sulfide absorption. Treated flue gas can incinerate use in dual Fuel dieselgenerator set for generation of electricity. After process remove the formed carbonous substance or residue in reactor to work as insulator for maintaining the efficiency of process.

\section{PROCESS DESCRIPTION:}

Thermal cracking process without catalyst was used in converting waste plastic into liquid fuel. Two types of waste plastic are selected for this particular experiment. By weight $50 \%$ of each Low density polyethylene and polypropylene was selected for the experiment. Both waste plastic are solid hard form. Collected waste plastic was cleaned using liquid soap and water. During waste plastics are cleaned is cerates waste water. This waste water is purified for reuse using waste water treatment process. Washed waste plastics are cut into $3-5 \mathrm{~cm}$ size to fit into the reactor conservatively. For experimental purpose we used $600 \mathrm{gm}$ sample $300 \mathrm{gm}$ of PP and $300 \mathrm{gm}$ of LDPE. A vertical steel reactor used forthermal cracking and temperature used ranges from $100^{\circ} \mathrm{C}$ to $400^{\circ} \mathrm{C}$. 
International Journal of Research in Advent Technology, Vol.7, No.4S, April 2019 E-ISSN: 2321-9637

Available online at www.ijrat.org

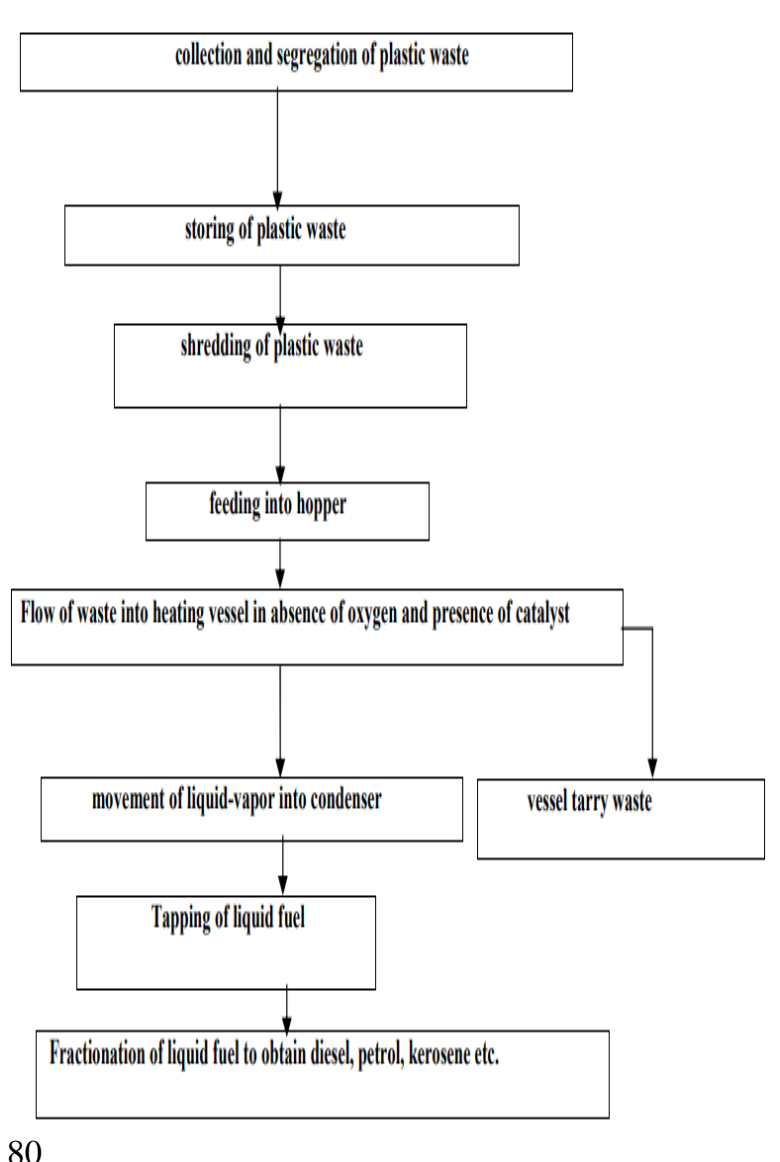

Figure 3- Conversion waste plastics into liquid fuel

\section{YIELD:}

The average percentage yield of various fuel fractions by fraction distillation depending on composition of waste plastics are Gasoline (60\%) and Diesel (30\%). The percentage of liquid distillate is mentioned in terms of weight by volume.

\section{GOOD PERFORMANCE:}

Liquid fuels from petroleum is diesel, petrol, kerosene require to mix various additives for improving burner and engine performance but fuel from waste plastics does not require to add these additives for work on burner and engines. Tarry waste or residue in reactor can use as solid fuel.

\begin{tabular}{|c|c|c|c|}
\hline St. $\mathrm{N}_{0 .}$ & Properties & $\mathrm{WPP}_{0}$ & Diessel \\
\hline 1. & Density(kg m²) & 793 & 850 \\
\hline 2. & Ash content $(\%)$ & $<1.01 \%$ wt & 0.045 \\
\hline 3. & Calorific value( $(\mathrm{J} / \mathrm{kg})$ & 41,800 & 42,000 \\
\hline \multirow[t]{2}{*}{4.} & Kinematic viscosity@ & 2.149 & 3.05 \\
\hline & $40 C(\operatorname{css})$ & & \\
\hline 5. & Cetane number & 51 & 55 \\
\hline 6. & Flassh point oC & 40 & 50 \\
\hline 7. & Fire point oC & 45 & 56 \\
\hline 8. & Carbon residue ( $\%$ ) & $0.01 \%$ wt & $0.20 \%$ \\
\hline 9. & Sulphur content $(\%)$ & $<0.002$ & $<0.035$ \\
\hline 10. & Pour point oC & -4 & 3.15 \\
\hline
\end{tabular}

\section{RESULTS AND DISCUSSION:}

By the process of Pyrolysis, plastics can be converted into fuel and in most scenarios three major products are obtained at the end of the process. These products are namely- Pyrolysis Oil, Carbon Black and a Gaseous mixture. All these three are arranged in order of their composition in the product. The properties of pyrolysis oil can be improved by hydrogenation. The pyrolysis oil is a good substitute of conventional fuel it is found that the oil when blended with conventional fuel like petrol \& diesel shows same characteristics as pure fuel dose. It is worth mention to notify that not only pure plastics but also plastics in which additives were used can be treated to form equally good oil. Thermal and catalytic pyrolysis has their own yield aspects for different products. It has been found that can be opted thermal pyrolysis for Liquid products and to catalytic pyrolysis can be preferred for Gaseous products.

\section{CONCLUSION}

Plastic waste liquid fuel is good substitute for obtaining new energy resource and eliminate greater problem of plastics waste management. In India more than 10 million ton of plastics waste generated in 2018. Inappropriate management of plastics gives perilous problem to human and environment. Mechanical recycling is not effective to reduce problem of plastics waste. Incineration, gasification , blast furnace are other methods does not effectively eliminate to this problem due to air pollution, economical impracticality compare to waste plastics fuel method. Biodegradable plastics are not meet at same rate as petroleum based plastics. Evolution of energy demand due to urbanization, population, industrialization and also increased price of fuel need 


\section{Available online at $w w w . i j r a t . o r g$}

to reduce to this demand and increased rate of fuel. Waste plastics fuel is ecofriendly due to low content of pollutants, good performance characteristics on engine, burner with no added any additives like lubricants and good viability with earning profit.

\section{REFERENCES:}

[1] Feed stock refining and pyrolysis of waste plastics by John Scheirs and Waller Kaminski.

[2] http://www.inspirationgreen.com/plasticwaste-as-fuel.html

[3] http://biomassmagazine.com/articles/2067/po wer-and-fuelfrom-plastic-wastes.

[4] Worner, Timothy. 2011. "Why and How to Baseline Your Extruder." Plastic Technology, August 2011.

[5] Onu P. Vasile C. Ciocilteu S. Iojoiu S. Darie $\mathrm{H}$. thermal and catalytic decomposition of polyethylene and polypropylene. Journal of analytic and applied pyrolysis 1999.

[6] Lee KH. Shin DH. Thermal degradation of waste polyolefin polymers using spent FCC catalysts with various experimental variables. Korean journal of chemical engineering 2003.

[7] V.P. MohanaJeyaValli, G. Gnanavel, M. Thirumarimurugan and D T. Kannadasan, Elixir Chem. Engg. 54 (2013) 12215-12218.

[8] MoinuddinSarker, Journal of Petroleum Technology and Alternative Fuels Vol. 2(8), pp. 141-145, August 2011.

[9] Antony Raja and AdvaithMurali, 2011 Conversion of Plastic Wastes into Fuels Journal of Materials Science and Engineering B 1 (2011) 86-89

[10] Birley, A. W., Heath, R. J., and Scott, M. J. (1988) Plastics Materials. Blackie, 2nd ed. introductory scientific textbook.

[11] Central Pollution Control Board. Study on solid waste management CPCB Delhi. (2003).

[12] Environment Protection Agency, U.S.A. Study on solid waste management (2011).

[13] Ministry Of Environment and Forest. News letter on solid waste management, New Delhi, (2007)

[14] PawarHarshal R. and LawankarShailendra M.(2013) Waste plastic Pyrolysis oil Alternative Fuel for CI Engine - A Review Research Journal of Engineering Sciences ISSN 2278 - 9472 Vol. 2(2), 26-30, February (2013)

[15] P.K Parikh PhD, Y.C Rotliwala (2008) DOI: 10.1680/warm.2008.161.2.85 ISSN: 17476526

[16] S Rao, Dr. B.B Parulekar (2012) Energy Technology NONCONVENTIONAL, RENEWABLE \& CONVENTIONAL),
Khanna Publishers, ISBN NO. 81-7409-0401.

[17] Tiwari D.C., Ejaz Ahmad, Kumar Singh K.K. Catalytic degradation of waste plastic into fuel range hydrocarbons International Journal of Chemical Research, ISSN: 0975- 3699, Volume 1, Issue 2, 2009, pp-31-36 10. UNEP, Converting Waste Plastics into Resource, (2009). 